the national to the community level to address IPV. The objective of this study was to describe the views and experiences of women living with HIV/AIDS of a government available system addressing IPV at the community level at Singida Regional Hospital in central Tanzania.

Methods This was a qualitative study involving in-depth interviews (IDIs); content analysis was used to analyse the findings.

Results The study suggests that there is a functional government system starting from the street chairperson, progressing through the police and legal systems up to the national level. IPV survivors were afraid to report their male partners to the police and legal system because of their fear of retaliation, loss of financial support, divorce and death, and their concern about who would care for their children. Also there were no psychosocial services at the community level. However, survivors of IPV end their IPV cases at the lower level of chairperson of the village. The findings suggest that there are no shelter services for IPV survivors in their community to provide for their basic needs.

Discussion Our study showed that women living with HIV/AIDS report IPV to the chairperson of their village, in-laws and their parents rather than the police or legal officer due to fear of retaliation, lack of economic support, concern for their children, lack of support from family and friends, stigma and fear of losing custody of children associated with divorce, and the fear that their partners will kill them.

Conclusions Our study concludes that the government of Tanzania needs to provide health education to communities about using the available government system to address IPV cases, to enhance community empowerment, especially for women living with HIV/AIDS, and to build safe homes for IPV survivors in the communities. We strongly recommend strict policies relating to men who inflict IPV on their female partners and strong action must be taken against them.

\section{RESTORATIVE JUSTICE IN CASES OF DOMESTIC VIOLENCE}

${ }^{1}$ Saija Sambou, ${ }^{2}$ Pia Slögs. ${ }^{1}$ Ministry of Justice, Finland; ${ }^{2}$ Yöjalka, Finland

10.1136/injuryprev-2016-042156.433

Background The study is part of a European comparative research and development project (JUST/2013/JPEN/AG/4587) which focuses on restorative justice methods and especially victim-offender-mediation in intimate partner violence cases aiming at increasing mutual understanding and awareness of specific protection needs. The starting point for the study was to recognise the critical questions raised particularly in regard to the protection of the victim but not to ignore the potential advantages which were reflected through empirical data.

Methods The results from Finland presented here are based firstly on interviews with victims and offenders. Out of the 12 respondents eight were women and four were men. Secondly, focus group interviews were made with prosecutors and police, who refer cases to mediation. Qualitative semi-structured interviews were conducted.

Results In Finland the vast majority of cases were situational violence connected to alcohol use. The respondents had various reasons for attending VOM. Victims needed their partners to listen to them, understand their feelings, to be taken seriously and to have a dialogue. Both victims and offenders were however hoping to avoid a trial. The mediation process and the mediators' efforts were appreciated by victims and offenders. Almost all victims felt safe during VOM and parties received information on services. Experiences were mainly positive and resulted in an agreement. Although the results sometimes were temporary, the situation improved in most cases.

Conclusions Developing the training and practices is important. Risk assessment and awareness of IPV phenomena, as well as the case selection with emphasis on the parties' abilities needs to be developed. Handled appropriately and in a victim sensitive manner, VOM can help prevent reoffending, make victims stronger and give parties new angels of thinking.

\section{PREVALENCE OF BULLYING VICTIMISATION AMONG STUDENTS WITH DISABILITIES IN THE UNITED STATES}

${ }^{1}$ Caroline I McNicholas, ${ }^{2}$ Pamela Orpinas. ${ }^{1}$ Towson University, USA; ${ }^{2}$ University of Georgia, USA

10.1136/injuryprev-2016-042156.434

Background Bullying refers to repeated aggression in relationships with an imbalance of power. Children with disabilities experience more bullying than children without disabilities, but research with this population is scarce. The objective of this retrospective, mixed-methods study was to examine the prevalence and characteristics of bullying victimisation among students with disabilities.

Methods Participants were 161 college students with disabilities, who were registered at the university's Disability Resource Centre. The sample was mostly female (78\%), White (62\%), and full-time students (90\%). The mean age of participants was 22.4 years. Participants completed an electronic survey, which queried respondents about frequency of physical, verbal, relational, and cyber bullying victimisation during middle and high school. The survey also included open-ended questions about examples of bullying and a selected sample was interviewed $(n=10)$.

Results The majority of participants (69\%) experienced bullying victimisation during middle and high school. Relational bullying was the most common type of victimisation reported (63\%), followed by verbal (38\%), cyber (24\%), and physical (18\%). Approximately $40 \%$ of participants reported they believed the aggression was related to their disability. Most of the aggression took place during middle school $(35 \%)$ or in both middle and high school (26\%). Participants with Pervasive Developmental Disorders experienced the highest level of bullying victimisation, followed by Learning Disabilities, Sensory Disorders, and Psychological Disorders. Unexpectedly, some participants reported bullying from teachers and school staff. Examples of bullying are provided.

Conclusions Participants in this study experienced bullying at a rate that is 3 times higher than students from the general population. Suggestions for intervention and further research are discussed.

\section{EFFECTIVENESS OF ANTI-COPORAL PUNISHMENT EDUCATION PROGRAM AMONG PARENTS IN CHILD CENTRES IN BANGKOK}

Chatchai Im-arom, Chaiwat Rerkswattavorn, Adisak Plitponkarnpim. Mahidol University, Thailand

10.1136/injuryprev-2016-042156.435 